\title{
An Implementation of Fuzzy PD Control Design for Five Flip Folders Folding Machine Using Arduino Mega2560
}

\author{
Wahyu S Pambudi ${ }^{*}$, Efrita A Zuliari², Riza A Firmansyah ${ }^{3}$, M Hasbi Nasiruddin ${ }^{4}$ \\ Electrical Engineering Department, Adhi Tama Institute of Technology (ITATS), Jalan Arief Rahman Hakim no. 100, \\ Surabaya 60117, Indonesia \\ I'wahyusp@itats.ac.id*; ${ }^{2}$ efrita.zuliari@gmail.com; ${ }^{3}$ rizaagungf@itats.ac.id; ${ }^{4}$ hasbihayra@gmail.com \\ *wahyusp@itats.ac.id
}

ARTICLE INFO

ABSTRACT

Article history:

Received : 29 April 2019

Revised : 30 July 2019

Accepted : 04 Oct 2019

Keywords:

Fuzzy PD

ARX

Folding Machine

Five Flip Folders

Microcontroller
The arm manipulator application with 1 degree of freedom (DOF) might be used to flip folders in folding machines. In this study, the actuator used is a Brushed DC motor. Generally, the Fuzzy-PD control system was applied using Arduino Mega2560 microcontroller and move five flip folders in real-time, becoming a novelty. It improves the system response in case there is a load, with a difference of $7.73 \%$. Moreover, to implement this flip folder, a stochastic based method (ARX) is applied for it to be simulated directly. The simulation results s have a time constant of $0.510 \mathrm{~s}$, rise time of $1.501 \mathrm{~s}$, settling time of $1.5320 \mathrm{~s}$ and delay time of $0.353 \mathrm{~s}$.

Copyright $@ 2017$ International Journal of Artificial Intelligence Research. All rights reserved.

\section{Introduction.}

In the previous study, the arm manipulator application had 1 degree of freedom (DOF) with three-fold folders forming a folding machine prototype. The actuator in the prototype of the folding machine uses Brushed DC motor with a combined proportional-integral-derivative (PID), and a fuzzy logic control system implemented on the LEGO Mindstorms EV3 robot module [1]. Generally, the combined Fuzzy control system with PID has a better response where arm manipulator motion reaches the specified object point with minimum errors, less peak overshoot and better rejection of disturbances [1][2][3][4][5][6][7][8][9]. This folding machine prototype model cannot be applied realistically since the used mechanical material of the robot module is designed for educational purpose. The folding machine prototype has three flip folders with 3 Brushed DC motor actuators, and therefore there are only 3 folds in the system. To practically make this folding machine, research needs to be carried out. In this study, the development of a folding machine prototype has five flip folders which use the principle of arm manipulator with $1 \mathrm{DOF}$, and a Fuzzy joint control system with PID or Fuzzy Proportional Derivative (Fuzzy PD). The novel of this research is the Fuzzy PD system application to control 5 flip folders with 1 DOF since similar research only uses 3 flip folders with 1 DOF [1]. From the previous study, to get a specific position, the PID control system was used by adding heuristics [10][11][12][13]. This is the first study to control 5 flip folders with 1 DOF in folding machines on the Fuzzy-PD control system. Nevertheless, it is a continuation of previous research on identifying statistical models using the Autoregressive with Exogenous (ARX) approach [14]. The modelling form of the plant control system is the most fundamental part in determining it's characteristic and helps to design the right controller and produce excellent performance [6][15][16][17]. In the previous study, the PID method was used only to optimize and simulate the system model response. In contrast, this study carried out several experiments in real-time to determine the application of fuzzy logic control and PID concept (Fuzzy PD) [1][7][18][19]. Additionally, this study examined further the response of 5 DC motors used in 1 DOF folding machine. Actuators in flip folders use EMG30 brushed DC motors equipped with a rotary encoder. This folding machine is designed to fold clothes and serve as a base for tidying them. 


\section{Research Method}

Figure 1 shows the hardware design for the system, consisting of 5 flip folders where the actuator uses EMG30 and has a position feedback sensor called rotary encoder. This rotary encoder is connected to the EMG30 motor DC shaft. The central processing unit for the system uses Arduino Mega 2560 equipped with PWM outputs and counters to calculate the rotary encoder.

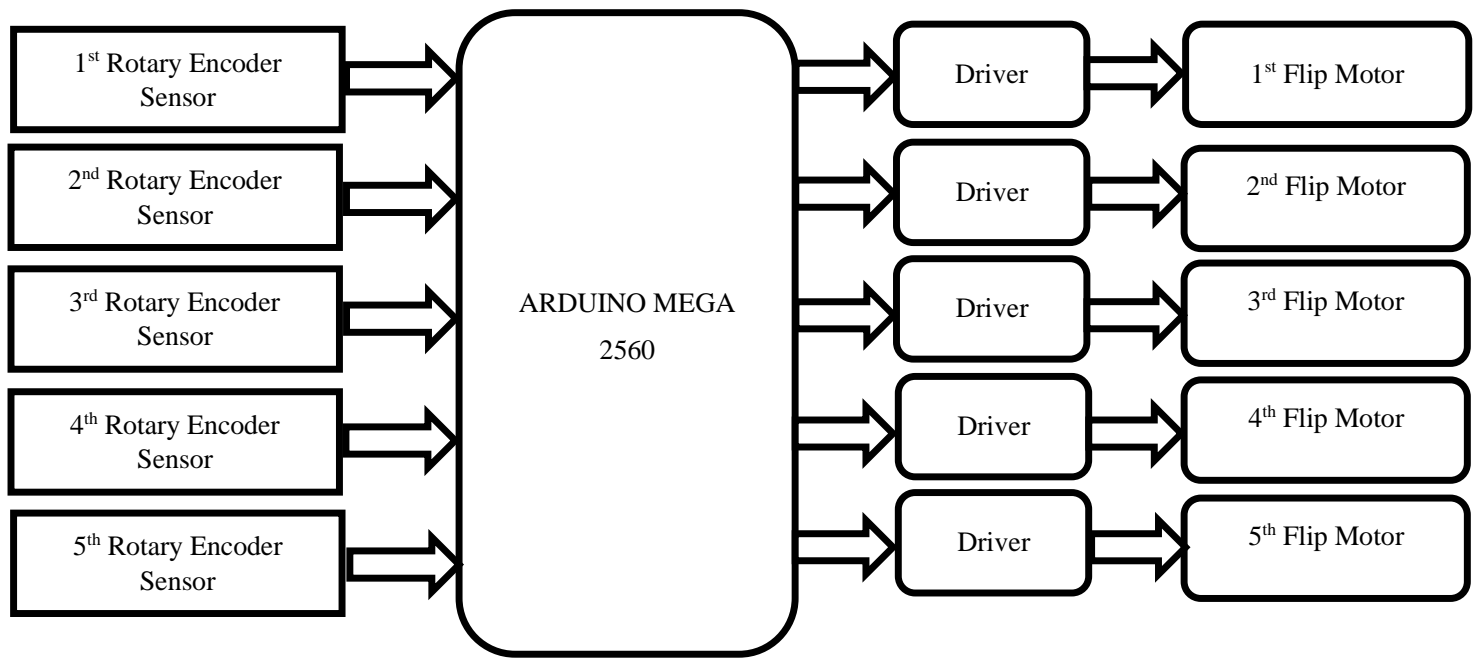

Fig. 1. Hardware System

The rotary encoder is used to read the motor rotation, and its output is connected to a pull-up resistor and buffer as an output signal amplifier. The output signal from the rotary encoder is sent to the Mega 2560 Arduino Microcontroller input pin to be processed as PID and Fuzzy-PD input. The PID and Fuzzy-PD control output is in the form of a PWM connected to a DC motor. In DC shafts, this motor is associated with two-link arm manipulators, while the end of effectors (EE) is connected directly to the flip folder, as shown in fig. 2.a. Fig. 2.b shows the position of each flip folder in the folding machine.



(a)

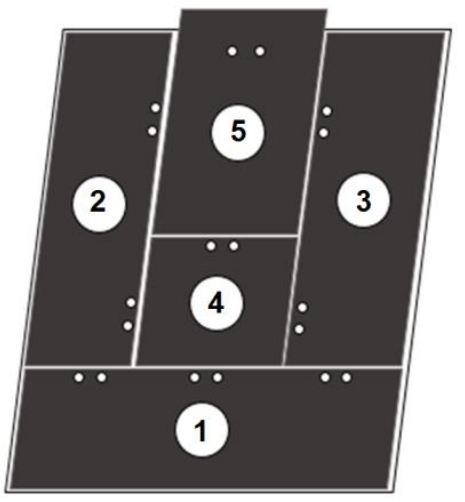

(b)

Fig. 2. a. DC Motor Shaft with two-link arm manipulators, b. Fold folder position in a folding machine

Based on fig.2.a, 2.1 is DC motor shaft, 2.2a and 2.2b are two link arm manipulators, 2.3 is EE and 2.4 is flip folder from folding machines. In case the DC motor is working, the two link arm manipulator moves, EE is connected to the flip folder and opens or closes with only 1 DOF. Folding machine design with 5 flip folders is a development of the previous research which only uses 3 flip folders [1]. Therefore, the speed of opening and closing flip folders might be controlled based on the 
needs of the used control by Fuzzy-PD. Figure 3 shows the used Fuzzy-PD control block for a folding machine.

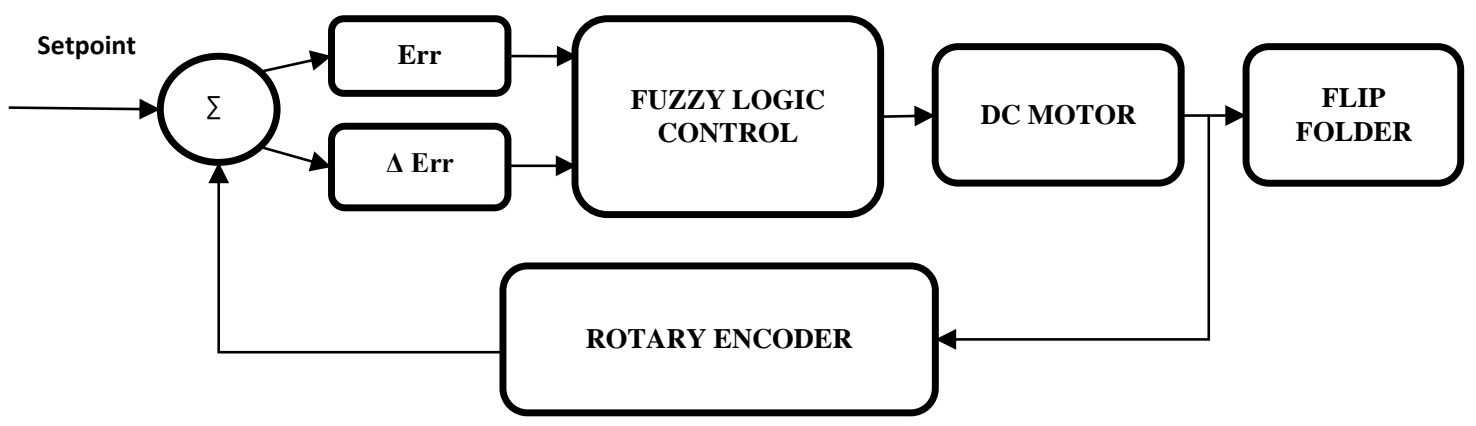

Fig. 3. Block Control of Folding Machine

The Fuzzy-PD control is used in the folding machine due to its advantages over conventional controls such as PI or PID. This advantages include; the system is able to reduce oscillation, lessens overshoot, cut settling time, and it is suitable for non-linear processes [20], [21], [22], [23], [24], [21], [25], [26], [27], and [28]. Fuzzy-PD uses input and delta $(\Delta)$ errors from the rotary encoder data which has been converted into an angle. These inputs procedes to the fuzzification process, where the input variable is made of two membership functions (MBF) referred to as Count Err MBF and MBF Count $\triangle$ Err as shown in fig. 4. The Count Err data is obtained from the setpoint value less the rotary encoder reading, while the data Count $\Delta$ Err is obtained from the current error value minus the previous [26][27][29][30].

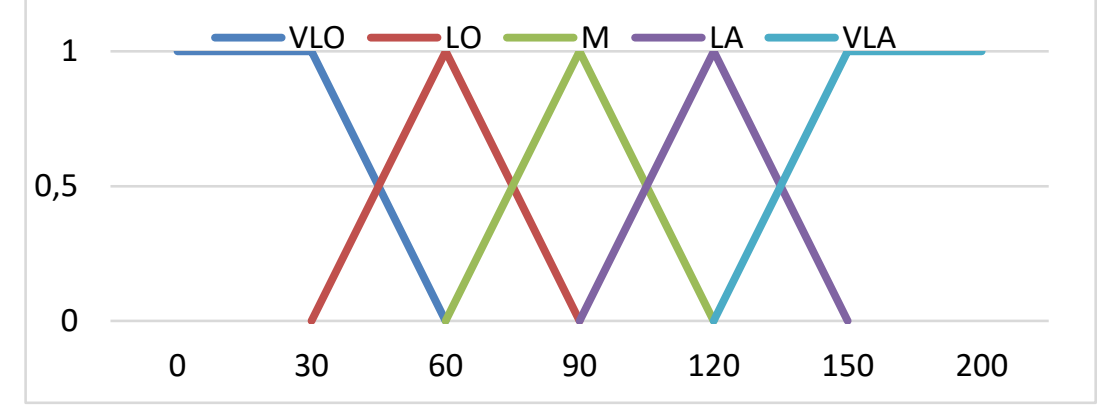

Fig. 4. Membership Function of Count Err dan $\Delta$ Err.

Each MBF is divided into 5 sections. The MBF Count Err and Count $\triangle$ Err are given the notations $\mathrm{VLO}=$ Very Low, $\mathrm{LO}=$ Low, $\mathrm{M}=$ Medium, $\mathrm{LA}=$ Large and VLA = Very Large. Figure 5 explains the MBF design for the output of this control system.

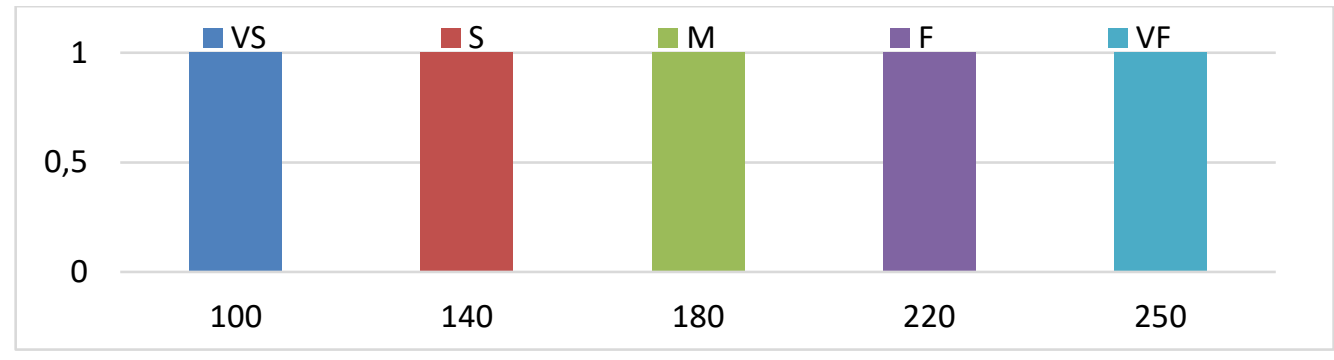

Fig. 5. Membership Function of Output Value.

The MBF for output function has 5 sets with the notations VS = Very Slow, S: Slow, M = Medium, $\mathrm{F}=$ Fast and VF = Very Fast. In fuzzy control, there is a rule evaluation function to produce output values as listed in Table 1 below. 
Table 1. Rule Evaluation

\begin{tabular}{|c|c|c|c|c|c|c|}
\hline & \multirow{2}{*}{ Err } & \multicolumn{5}{|c|}{ Count Err } \\
\hline$\Delta$ Erı & & $V L O$ & LO & $M$ & $L A$ & $V L A$ \\
\hline \multirow{5}{*}{ 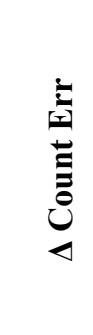 } & $\triangle \mathrm{VLO}$ & VS & $\mathbf{S}$ & $\mathbf{M}$ & $\mathbf{M}$ & $\mathbf{M}$ \\
\hline & $\Delta \mathrm{LO}$ & $\mathbf{S}$ & $\mathbf{S}$ & $\mathbf{M}$ & $\mathbf{M}$ & $\mathbf{F}$ \\
\hline & $\Delta \mathrm{M}$ & $\mathbf{S}$ & $\mathbf{S}$ & $\mathbf{M}$ & $\mathbf{F}$ & $\mathbf{F}$ \\
\hline & $\Delta \mathrm{LA}$ & $\mathbf{S}$ & $\mathbf{S}$ & $\mathbf{M}$ & $\mathbf{F}$ & VF \\
\hline & $\triangle \mathrm{VLA}$ & $\mathbf{M}$ & $\mathbf{M}$ & $\mathbf{F}$ & VF & VF \\
\hline
\end{tabular}

\section{Results And Analysis.}

The first stage of testing performance of Fuzzy-PD control on a folding machine involves examining a Fuzzy-PD simulation approach using a folding machine model with ARX approach. The plant parameters are collected through measuring input and output data in offline mode [14]. Based on the ARX process, a folding machine model is obtained, as shown in equation 1 and simulated using Fuzzy PD control. Figure 6 shows the block system of Fuzzy-PD control simulation for Flip Folder, while its response is presented in figure 7.

$$
\frac{18.28 s+4.605 \times 10^{-4}}{s^{2}+1286 s+4.622 \times 10^{-4}}
$$

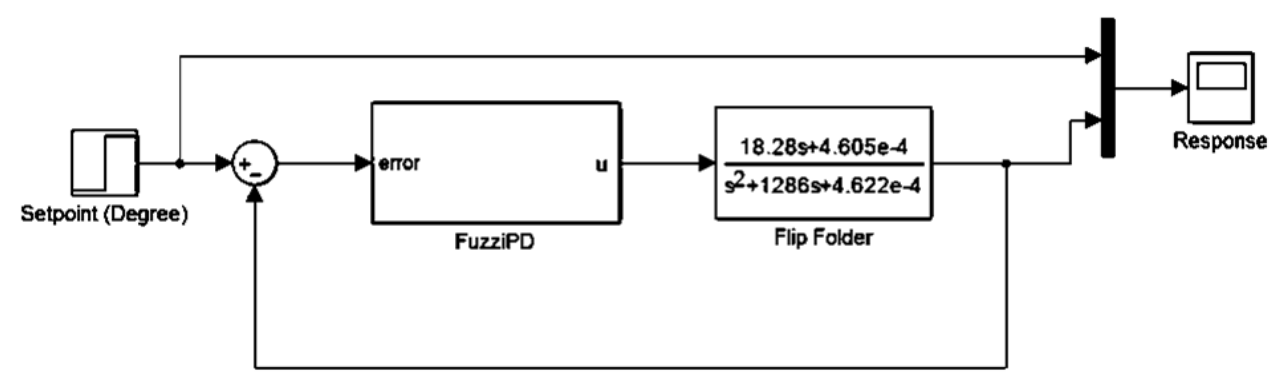

Fig. 6. Block System of Fuzzy-PD Control Simulation for Flip Folders

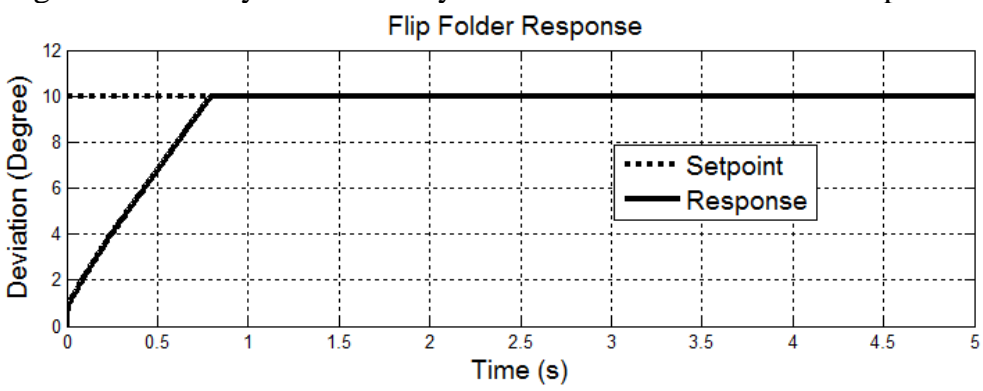

Fig. 7. The response of Fuzzy-PD Control Simulation for Flip Folder

Based on fig. 7, the response has a time constant $(\tau)=0.510 \mathrm{~s}$, rise time $=1.501 \mathrm{~s}$, settling time $=$ $1.5320 \mathrm{~s}$ and delay time $=0.353 \mathrm{~s}$. There is a difference between the fold folder angle and the angle on the DC motor shaft in the mechanical design of the folded folder. Table 2 shows the difference and explains the result of data retrieval from the fold folder angle with 5 shafts of DC motor.

Table 2. Comparison of Flip Folder Angles with 5 DC Motor Shafts 


\begin{tabular}{|c|c|c|c|c|c|}
\hline $\begin{array}{c}\text { flip folder angle } \\
\text { (degree) }\end{array}$ & $\begin{array}{c}1^{\text {st }} \text { DC Motor } \\
\text { (degree) }\end{array}$ & $\begin{array}{c}2^{\text {nd }} \text { DC Motor } \\
\text { (degree) }\end{array}$ & $\begin{array}{c}3^{\text {rd }} \text { DC Motor } \\
\text { (degree) }\end{array}$ & $\begin{array}{c}4^{\text {th }} \text { DC Motor } \\
\text { (degree) }\end{array}$ & $\begin{array}{c}5^{\text {th }} \text { DC Motor } \\
\text { (degree) }\end{array}$ \\
\hline 210 & 218 & 24 & 22 & 22 & 20 \\
\hline 30 & 62 & 69 & 67 & 60 & 46 \\
\hline 40 & 79 & 86 & 91 & 80 & 58 \\
\hline 60 & 110 & 124 & 129 & 112 & 76 \\
\hline 70 & 122 & 143 & 146 & 129 & 84 \\
\hline 90 & 148 & 171 & 175 & 156 & 100 \\
\hline 100 & 160 & 185 & 189 & 166 & \\
\hline 120 & 181 & 210 & 214 & 194 & \\
\hline 130 & 191 & 225 & 228 & 204 & \\
\hline 150 & 207 & 249 & 250 & 228 & \\
\hline
\end{tabular}

The analysis of folding machine performance begins by giving a step signal as an input to 5 flip folders, as shown in fig. 8 to 12. Setpoint in a folding machine is based on angle shaft of DC motor, settled to $200^{\circ}$. In case it is converted to flip folder angle using a polynomial approach, the flip folder one is $138.59^{\circ}$, flip folder two $109.55^{\circ}$, flip folder three $106.90^{\circ}$ and flip folder four $124.08^{\circ}$. It was different from the previous setpoint of the DC motor Shaft angle with setpoint five $=40^{\circ}$. In case it is converted to the fold folder, the angle $=24.15^{\circ}$. The results of the polynomial parameters are listed in table 3 below.

Table 3. Polynomial approach from the angle shafts of DC motor to the fold corner

\begin{tabular}{ccccc}
\hline DC motor & a0 & a1 & a2 & error (\%) \\
\hline \hline 1 & 0.002 & 0.279 & 4.9462 & 1.340 \\
2 & 0.001 & 0.3487 & 1.3082 & 1.044 \\
3 & 0.0012 & 0.2815 & 4.1249 & 1.882 \\
4 & 0.0011 & 0.4048 & 0.8039 & 1.208 \\
5 & 0.0006 & 0.933 & -12.1686 & 6.349 \\
\hline
\end{tabular}
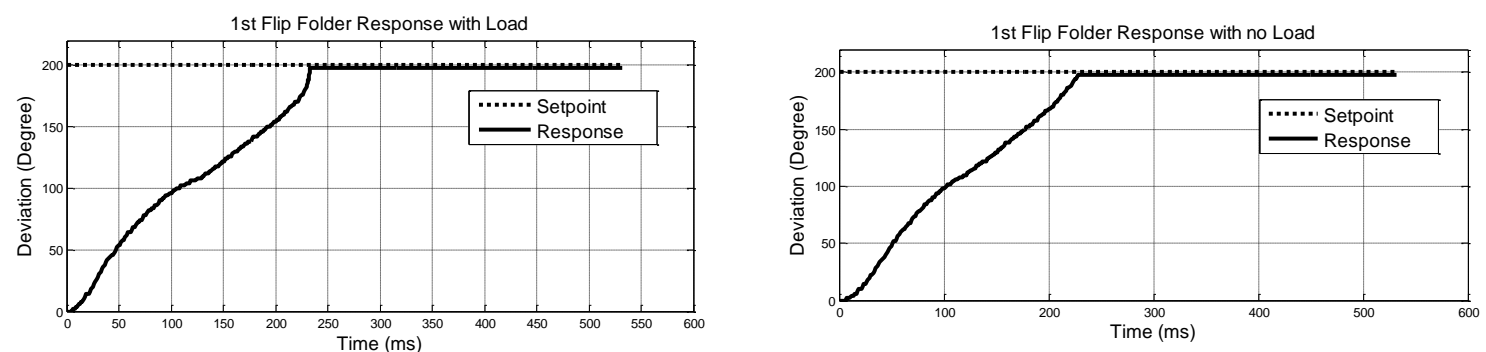

Fig. 8. The response of the 1st flip folder with load and without load

Fig. 8 shows the response of the first DC motor with load and no-load conditions. The no-load rise time is $230 \mathrm{~ms}$ and $236 \mathrm{~ms}$. With the load is exist, there was a difference of $6 \mathrm{~ms}$ between them. 

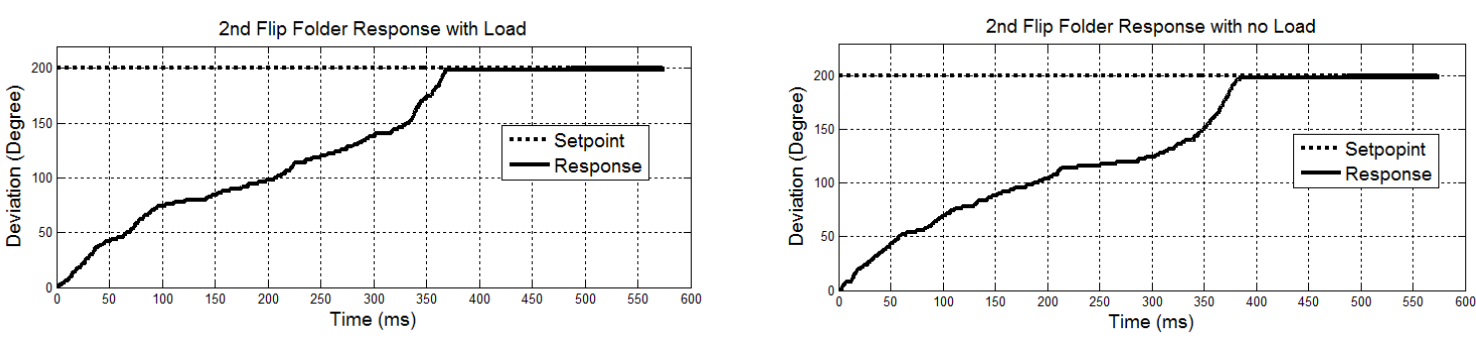

Fig. 9. The response of the 2nd flip folder with load and without load

In fig. 9. The response of the second DC motor has a rise in time without a load of $370 \mathrm{~ms}$ and $386 \mathrm{~ms}$. In case the load exist, there is a change of $16 \mathrm{~ms}$.
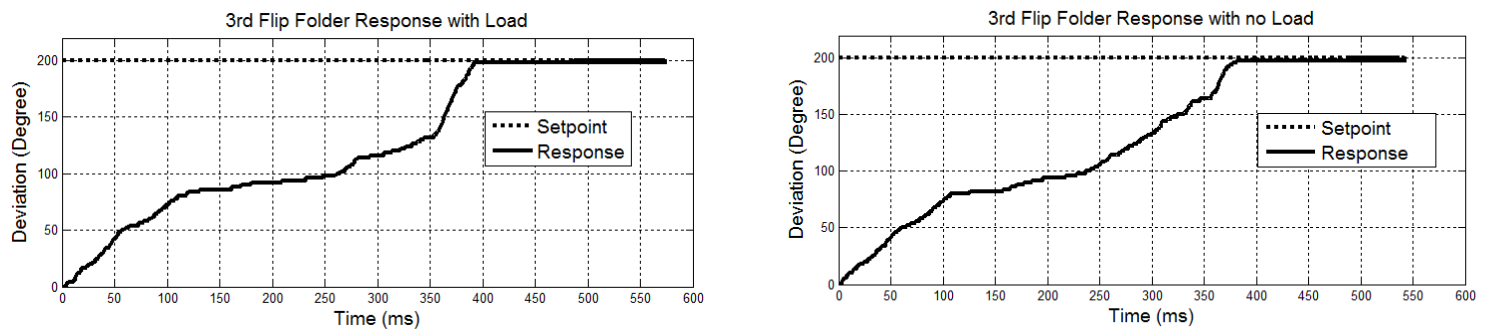

Fig. 10. The response of the 3rd flip folder with load and no load.

In fig. 10, the response of the third DC motor has a rise time without a load of $384 \mathrm{~ms}$, and when there is a load of $394 \mathrm{~ms}$, a change of $10 \mathrm{~ms}$ are occurs.
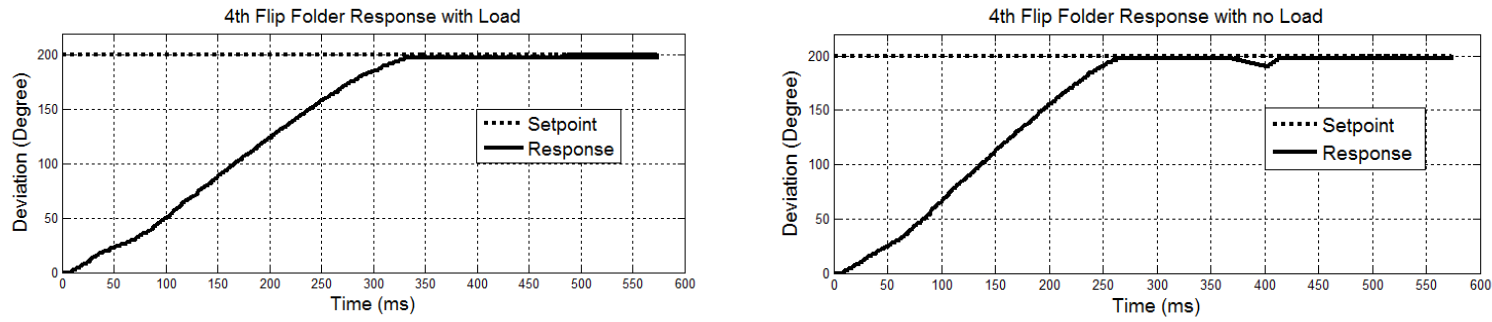

Fig. 11. The response of the 4th flip folder with load and without load.

In fig. 11 , the response of the fourth DC motor has a rise time without a load of $263 \mathrm{~ms}$ and $326 \mathrm{~ms}$. There is a change of $63 \mathrm{~ms}$ when the load is given.
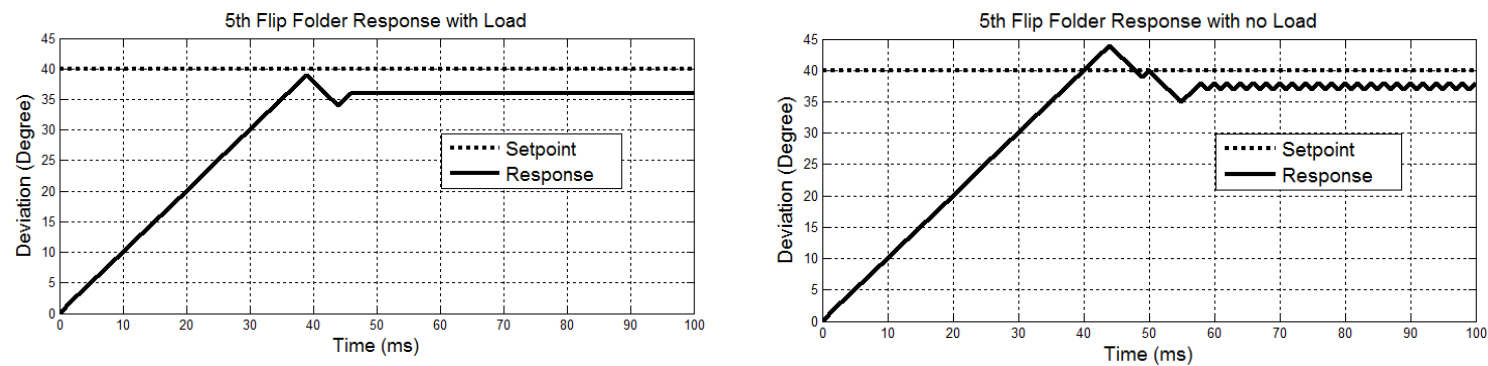

Fig. 12. The response of the 5th flip folder with load and without load.

In fig. 12, the response of the fifth DC motor without load is $38 \mathrm{~ms}$. There is a rise time equal to $40 \mathrm{~ms}$ with the load. 


\section{Conclusion.}

The principle of 1 DOF robot arm manipulator is used to control the flip folders in folding machines. The Fuzzy-PD has been successfully implemented in the Arduino Mega2560 microcontroller. In this study, the analysis has been carried out in simulation and real-time mode. Based on the response of control simulation, the flip folder model has a time constant response $(\tau)=$ $0.510 \mathrm{~s}$, rise time $=1.501 \mathrm{~s}$, settling time $=1.5320 \mathrm{~s}$ and delay time $=0.353 \mathrm{~s}$. The flip folder model is achieved using stochastic approximation called ARX [14]. While implementing Fuzzy-PD control in folding machines, 5 flip folders might be moved alternately. The implementation of Fuzzy-PD control for 5 flip folders is a development of the previous research which had only 3 flip folders [1]. The use of Fuzzy-PD control for the flip folder is able to overcome the interference due to the load, and the average difference in the rise time of both conditions is $7.73 \%$.

\section{Acknowledgements}

The authors express their sincere gratitude to DRPM Ristekdikti and Adhi Tama Institute of Technology (ITATS) for their assistance in facilities and funds. This research might be useful for technology development in Indonesia, especially in applied engineering.

[1] W. S. Pambudi and T. Suheta, "Implementation of Fuzzy-PD for Folding Machine Prototype Using LEGO EV3," TELKOMNIKA (Telecommunication Comput. Electron. Control., vol. 16, no. 4, p. 1625, 2018.

[2] P. Kumar, P. K. Prabhat, M. Kumar, and S. D. Choudhary, "Speed-Control-of-DC-Motor-Using-PIDSmart-Controller," Int. J. Sci. Eng. Res., vol. 5, no. 11, pp. 1044-1053, 2014.

[3] Q. Chen, W. Li, and G. Chen, "FUZZY P+ID Controller for a Constant Tension Winch in a Cable Laying System,” IEEE Trans. Ind. Electron., vol. 64, no. 4, pp. 2924-2932, 2017.

[4] P. I. Lin, S. Hwang, and J. Chou, "Comparison on Fuzzy Logic and Pid Controls for a Dc Motor," Ind. Appl. Soc. Annu. Meet. 1994., Conf. Rec. 1994 IEEE, pp. 1930-1935, 1994.

[5] E. Eke, "Using Simulink, Matlab, and LEGO Mindstorms to Teach a Project-Based Control Systems Design Course," pp. 26.1680.1-26.1680.25, 2015.

[6] B. C. Ng, I. Z. M. Darus, H. Jamaluddin, and H. M. Kamar, "Dynamic modelling of an automotive variable speed air conditioning system using nonlinear autoregressive exogenous neural networks," Appl. Therm. Eng., vol. 73, no. 1, pp. 1255-1269, 2014.

[7] W. S. Pambudi, E. Alfianto, A. Rachman, and D. P. Hapsari, "Simulation design of trajectory planning robot manipulator," Bull. Electr. Eng. Informatics, vol. 8, no. 1, pp. 196-205, 2019.

[8] S. Chopra, R. Mitra, and V. Kumar, "Analysis of Fuzzy PI and PD type controllers using subtractive clustering," vol. 4, no. 2, pp. 30-34, 2006.

[9] J.-Y. Lee, H.-R. So, Y.-H. Lee, S.-J. Oh, G.-G. Jin, and M.-O. So, "Fuzzy PD plus I Controller of a CSTR for Temperature Control,” J. Korean Soc. Mar. Eng., vol. 39, no. 5, pp. 563-569, 2015.

[10] I. Iswanto, O. Wahyunggoro, and A. Imam Cahyadi, "Quadrotor Path Planning Based on Modified Fuzzy Cell Decomposition Algorithm," TELKOMNIKA (Telecommunication Comput. Electron. Control., vol. 14, no. 2, p. 655, 2016.

[11]A. Adriansyah, Y. Gunardi, B. Badaruddin, and E. Ihsanto, "Goal-seeking Behavior-based Mobile Robot Using Particle Swarm Fuzzy Controller," TELKOMNIKA (Telecommunication Comput. Electron. Control., vol. 13, no. 2, p. 528, 2015.

[12] W. Cao, L. Senhai, Y. Xiaoping, J. Jie, and Z. Wenhui, "Back-stepping Control of Free-Floating Space Robot based on Adaptive Neural Network," TELKOMNIKA (Telecommunication Comput. Electron. Control., vol. 15, no. 1, p. 18, 2017.

[13] R. Y. Putra et al., "Neural network implementation for invers kinematic model of arm drawing robot," in 2016 International Symposium on Electronics and Smart Devices, ISESD 2016, 2017, pp. 153-157.

[14] W. S. Pambudi, E. A. Zuliari, R. A. Firmansyah, Y. A. Prabowo, and A. Syaifurrizal, "Identification of Flip Folder Model on Folding Machine," in IOP Conference Series: Materials Science and Engineering, 2019, vol. 462, no. 1.

[15] S. A. Zulkeflee, S. A. Sata, and N. Aziz, "Auto-regressive with exogenous input model predictive controller for water activity in esterification," Chem. Eng. Trans., vol. 56, pp. 217-222, 2017.

[16] W. J. Tang, Z. T. Liu, and Q. Wang, "DC motor speed control based on system identification and PID auto tuning," in Chinese Control Conference, CCC, 2017, no. 61403422, pp. 6420-6423. 
[17] J. U. Liceaga-Castro, I. I. Siller-Alcala, J. Jaimes-Ponce, and R. Alcantara-Ramirez, "Series DC Motor Modeling and Identification," in Proceedings - 2017 International Conference on Control, Artificial Intelligence, Robotics and Optimization, ICCAIRO 2017, 2018, vol. 2018-Janua, no. November, pp. 248-253.

[18] S. A. Hamoodi and R. A. Mohammed, "DC Motor Speed Control Using PID Controller Implementation by Simulink and Practical," vol. 11, no. 1, pp. 39-49, 2018.

[19] S. P. Yadav, V. K. Tripathi, and M. T. Student, "A Case Study of DC Motor Speed Control with PID Controller through MAT LAB," Int. J. Adv. Res. Comput. Commun. Eng., vol. 5, no. 5, pp. 1008-1011, 2016.

[20]E. Mishra and S. Tiwari, "Comparative Analysis of Fuzzy Logic and PI Controller Based Electronic Load Controller for Self-Excited Induction Generator," Adv. Electr. Eng., vol. 2017, pp. 1-9, 2017.

[21]E. Kiyak and G. Gol, "A comparison of fuzzy logic and PID controller for a single-axis solar tracking system," Renewables Wind. Water, Sol., vol. 3, no. 1, 2016.

[22] C.-T. Chao, N. Sutarna, J.-S. Chiou, and C.-J. Wang, "Equivalence between Fuzzy PID Controllers and Conventional PID Controllers," Appl. Sci., vol. 7, no. 6, p. 513, 2017.

[23] M. S. Mohiuddin, "Performance Comparison of Conventional Controller with Fuzzy Logic Controller using Chopper Circuit and Fuzzy Tuned PID Controller," Indones. J. Electr. Eng. Informatics, vol. 2, no. 4, pp. 189-200, 2014.

[24] P. Mohindru, G. Sharma, and P. Pooja, "Simulation Performance of PID and Fuzzy Logic Controller for Higher Order System," Commun. Appl. Electron., vol. 1, no. 7, pp. 31-35, 2015.

[25]H. T. Yau, P. H. Yu, and Y. H. Su, "Design and implementation of optimal fuzzy PID controller for DC servo motor,” Appl. Math. Inf. Sci., vol. 8, no. 1 L, pp. 231-237, 2014.

[26] N. A. Dange and A. Pawar, "Position Control of Servo Motor Using Fuzzy," pp. 5541-5552, 2016.

[27]A. Tadesse and M. Jungong, "Modeling and simulations on a fuzzy- PID position controller of electro hydraulic servo system," 2015 12th Int. Conf. Fuzzy Syst. Knowl. Discov. FSKD 2015, vol. 4, no. 6, pp. 96-103, 2016.

[28] R. R. Serrezuela, M. Á. T. Cardoso, and A. F. C. Chavarro, "Design and implementation of a pid fuzzy control for the speed of a DC motor," ARPN J. Eng. Appl. Sci., vol. 12, no. 8, pp. 2655-2660, 2017.

[29]E. Kuantama, T. Vesselenyi, S. Dzitac, and R. Tarca, "PID and Fuzzy-PID control model for quadcopter attitude with disturbance parameter," Int. J. Comput. Commun. Control, vol. 12, no. 4, pp. 519-532, 2017.

[30]D. K. Tiep, K. Lee, D.-Y. Im, B. Kwak, and Y.-J. Ryoo, "Design of Fuzzy-PID Controller for Path Tracking of Mobile Robot with Differential Drive," Int. J. FUZZY Log. Intell. Syst., vol. 18, no. 3, pp. 220-228, 2018. 